\title{
Bidirectional avoidance by mice as a function of CS, US, and apparatus variables
}

\author{
GIORGIO BIGNAMI, ENRICO ALLEVA, LUIGI AMORICO, \\ LUIGI DE ACETIS, and VALERIO GIARDINI \\ Istituto Superiore di Sanita, Rome, Italy
}

\begin{abstract}
Acquisition of two-way avoidance by mice was slower with a light CS than with a buzzer CS, with punishment of intertrial responses than without punishment, and with a short CS-CS interval than with a long CS-CS interval (30 vs. $60 \mathrm{sec}$ ). Light-cued avoidance was little affected by shock level (.35-1.5 mA), whereas mice trained with the buzzer CS learned faster at $1.5 \mathrm{~mA}$. Animals required to move away from light or toward light showed comparable rates of acquisition. Other CS, US, and apparatus variables (directionality of cue, maximal shock duration, and presence vs. absence of a central partition in the shuttlebox) interacted in a complex fashion with those already mentioned. This resulted in widely differing performances in what may superficially appear to be different versions of the same task. The differences in mouse and rat responses to some of the variables can contribute to an understanding of the interactions between organismic and test factors and the relative explanatory value of alternative avoidance models.
\end{abstract}

Comparisons of escape-avoidance performance among several rodent species have suggested what some of the mechanisms underlying behavior regulation may be. For example, a strong locomotor bias in gerbils can explain their poor performance, compared with that of rats, in passive avoidance and their efficient performance in two-way active avoidance (Ashe \& McCain, 1972; Galvani, Riddell, \& Foster, 1975; Walters \& Abel, 1971). This bias can also explain why gerbils perform poorly in a two-way task if intertrial crossings are punished. In fact, in this situation, a high shock rate results from their inability to suppress locomotion (Osborne, Caul, \& Vanstrum, 1976).

Few efforts to confront alternative explanations of avoidance performance have been made with mice. In fact, a number of critical interactions known to occur with rats have yet to be assessed in mice trained in comparable conditions.

Rats and mice are closely related taxonomically, but they differ in important characteristics such as body size and pattern of activity (see below). Consequently, the present experiments focused on possible interactions between such factors as CS modality and directionality, shock (US) intensity and duration, intertrial-interval duration, intertrial-response consequences, and apparatus factors. It is appropriate to note here that this type of approach does not necessarily require a direct comparison, in the same experiments, of two or more species, particularly when fairly complex designs must be adopted for

This research was supported as part of the Subproject on Neurobehavioral Pathophysiology (main project: Noninfectious Pathology) of the Istituto Superiore di Sanità, Roma, Italy. We regret to report the death of Valerio Giardini on August 2, 1985. Reprint requests should be sent to the first author, Laboratorio di Fisiopatologia di Organo e di Sistema. Istituto Superiore di Sanità. Viale Regina Elena 299. I-00161 Roma, Italy. the purposes of the study. The comparison occurs, rather, at the level of the pattern of data generated.

\section{EXPERIMENTS 1A-1C}

The acquisition of bidirectional avoidance by rats is impaired by conditions that presumedly make the animal "reluctant" to return to the place of previous punishment. Such conditions include punishment of intertrial crossings (Bignami, Amorico, Frontali, \& Rosić, 1971; Schwartzbaum, Green, Beatty, \& Thompson, 1967; for a similar effect of intertrial response prevention, see Moot, Nelson, \& Bolles, 1974) and increases in shock intensity (Anisman \& Waller, 1972; Archer, Ögren, \& Johansson, 1984; Bauer, 1972; Bignami et al., 1971; Cicala, Owen, \& Hill, 1976; Henderson, 1970; Johnson \& Church, 1965; Levine, 1966; McAllister, McAllister, \& Douglass, 1971; Moyer \& Korn, 1964; Schwartzbaum et al., 1967; Theios, Lynch, \& Lowe, 1966). A similar assertion can tentatively be made with regard to the impairment of rat avoidance obtained by the use of a central partition with an opening of limited size at floor level (Bignami et al., 1971; Dalby \& Shuttlesworth, 1978; Henderson, 1970; for preexposure conditions modifying this effect, see Alleva, De Acetis, Amorico, \& Bignami, 1983). In fact, the periods of shock experienced by animals moving in a random fashion in the initial stages of training, before they learn to reach the safe part of the box, are more extended in the presence of a partition than in its absence.

Shock intensity and other related effects have generally been explained either by response competition models (Moyer \& Korn, 1964; Theios et al., 1966) or by reinforcement models (Dieter, 1977; McAllister et al., 1971; McAllister, McAllister, Dieter, \& James, 1979). However, the controversy on this point does not need to be considered for the purposes of the present work. 
In some mouse strains, bidirectional avoidance was unaffected or even facilitated by a high shock level (Carran, Yeudall, \& Royce, 1964; Royce, 1966). This result, however, may have been due to the use of a buzzer signal, because acoustic stimuli can be very effective as active avoidance CS (for differences between acoustic and visual signals in rat avoidance, see Biederman, 1967; Bolles, Hargrave, \& Grossen, 1970; Frontali \& Bignami, 1973, 1974; Jacobs \& LoLordo, 1977; Myers, 1964, 1977; Rosić, Frontali, \& Bignami, 1969; Schindler \& Weiss, 1982; Whittleton, Kostanek, \& Sawrey, 1965; for mice see Oliverio, 1967).

Experiment 1A (see Table 1) investigated the role of CS modality (light vs. buzzer noise), intertrial contingency (presence or absence of intertrial response punishment), and partition (present or absent). All mice were trained with a high shock intensity $(1.5 \mathrm{~mA})$. Experiment $1 \mathrm{~B}$ compared two shock intensities $(0.35$ and $1.5 \mathrm{~mA})$, along with CS modality and intertrial response punishment. The training of all mice was undertaken with a partition in place. Experiment $1 \mathrm{C}$ compared four different shock intensities $(.35, .6,1$, and $1.5 \mathrm{~mA})$ and either punishment or no punishment of intertrial crossings. In addition to the partition, all animals were trained with a light CS.

\section{Method}

Subjects. Naive male mice of an outbred Swiss-derived strain (CD-1), weighing 25-30 g, were obtained from Charles River Italia (22050 Calco, Italy). Upon arrival at the laboratory, the animals were housed in groups of 4 to 6 in $33 \times 15 \times 12 \mathrm{~cm}$ plastic cages (group size was constant throughout the experiment) and permitted ad-lib access to pellet food and water. Except during testing hours, when they were moved to the laboratory, the mice were kept in a conventional animal room with air conditioning (temperature $22^{\circ} \pm 1^{\circ} \mathrm{C}$, relative humidity $50 \% \pm 10 \%$ ), and artificial lighting from 6 p.m. to 6 a.m.

Apparatus. Eight $39 \times 9 \times 17 \mathrm{~cm}$ sound-insulated shuttleboxes (Ugo Basile, 21025 Comerio-Varese, Italy) were used either with or without a central partition that had a 4.5 -cm-diam circular opening. When the partition was fitted into the cage, part of the opening $(1 \mathrm{~cm}$ on the vertical diameter) was below the grid floor (see below); the maximal width of the opening itself was $1.25 \mathrm{~cm}$ above floor level. Two 3-W bulbs were on either side of the center of the ceiling. When the partition was absent, the light CS was always nondirectional. When the partition was used, the light CS could be either nondirectional (illumination of both compartments) or directional (only one side illuminated). A commercial buzzer (standard 200-250-V ac model made by Bassano Ticino, 20122 Milano, Italy, used without the plastic lid), which was placed between the shuttlebox and the sound-insulating container, provided a loud nondirectional noise signal (about $90 \mathrm{~dB}$ inside the shuttlebox). The oil-dampened tilting floor, which was constructed of $1.5-\mathrm{mm}$-diam rods spaced $7 \mathrm{~mm}$ apart, could be electrified by a mechanical scrambler and a $70-\mathrm{k} \Omega$ resistor in series (desired nominal intensity obtained by varying the voltage).

Procedure. All animals received 10 daily avoidance sessions in 2 consecutive weeks (Monday through Friday). Each session was made up of 50 trials, with an interval of $30 \mathrm{sec}$ between successive CS presentations and an interval of $5 \mathrm{sec}$ between onset of CS and onset of shock (US). A response during the CS-US interval terminated the CS and prevented shock; a response after US onset terminated both stimuli simultaneously. The maximal duration of CS and US together in the case of nonresponding was $10 \mathrm{sec}$. In Experiment $1 \mathrm{~A}$ (see Table 1), 9 mice were assigned at random to each of eight experimental conditions with nondirectional light or noise as CS, with or without punishment of intertrial responses, and with or without a central partition. The shock intensity was $1.5 \mathrm{~mA}$ for all groups. When the animals were shocked for intertrial responding, the CS was turned on for the duration of punishment, which lasted until the animal recrossed the shuttlebox.

In Experiment 1B (see Table 1), all animals were run with the central partition in place; the CS modality and the intertrialpunishment condition were varied as in Experiment $1 \mathrm{~A}$, and the shock intensity was either .35 or $1.5 \mathrm{~mA}(\mathrm{~N}=12$ in each of the eight groups). In all but an occasional mouse, the lower intensity produced escape but no other signs of distress. The higher intensity produced squealing, running, and jumping in all animals.

In Experiment 1C (see Table 1), all mice were run with the central partition in place and a nondirectional light CS; the independent variables were presence or absence of intertrial response punishment and four different shock levels $(.35, .6,1$, and $1.5 \mathrm{~mA} ; \mathrm{N}=12$ in each of the eight groups). This experiment was conducted mainly to ascertain whether or not a nonmonotonic (inverted- $U$ shaped) shock-intensity function was missed in Experiment 1B, using two widely differing shock levels.

All designs were completely counterbalanced with respect to assignment of animals to different shuttleboxes within each of the intertrial conditions and to different times of testing (same time for each animal in successive sessions). Testing occurred between

Table 1

Testing Conditions in Experiments 1-3

\begin{tabular}{|c|c|c|c|c|c|c|c|}
\hline \multirow[b]{3}{*}{ Experiment } & & & \multirow{3}{*}{$\begin{array}{c}\text { CS-CS } \\
\text { Interval } \\
(\mathrm{Sec})\end{array}$} & \multicolumn{2}{|c|}{ US } & \multirow{3}{*}{$\begin{array}{c}\text { Intertrial } \\
\text { Response } \\
\text { Punishment }\end{array}$} & \multirow[b]{3}{*}{ Partition } \\
\hline & \multicolumn{2}{|r|}{ CS } & & & $\begin{array}{l}\text { Maximal } \\
\text { Duration }\end{array}$ & & \\
\hline & $\overline{\text { Modality }}$ & Directionality & & $\mathrm{mA}$ & $(\mathrm{Sec})$ & & \\
\hline $1 \mathrm{~A}$ & L,B & No & 30 & 1.5 & 10 & No, Yes & No, Yes \\
\hline $1 \mathrm{~B}$ & $\mathrm{~L}, \mathrm{~B}$ & No & 30 & $.35,1.5$ & 10 & No, Yes & Yes \\
\hline 1C & $\mathrm{L}$ & No & 30 & $\begin{array}{l}.35, .6 \\
1,1.5\end{array}$ & 10 & No, Yes & Yes \\
\hline 2 & L & $\begin{array}{l}\text { Yes (Away } \\
\text { vs. Toward) }\end{array}$ & 30 & $.35,1.5$ & 10 & No, Yes & Yes \\
\hline $3 \mathrm{~A}$ & $\mathrm{~L}$ & $\begin{array}{l}\text { No, Yes } \\
\text { (Away) }\end{array}$ & 30,60 & 1.5 & 10 & No & Yes \\
\hline 3B & $\mathrm{L}$ & No & 30,60 & 1.5 & 5,10 & No & No, Yes \\
\hline
\end{tabular}

Note-The stimulus was turned on at the beginning of each trial and was terminated by the response. The buzzer $(B)$ was always nondirectional (source outside the box). The light $(L)$ was turned on in both compartments (nondirectional), only in the start compartment (directional "go away"), or only in the opposite compartment (directional "go toward"). 
8:30 a.m. and 3:30 p.m., that is, in the dark hours of the reversed cycle, and the animals were kept for only a limited time in the illuminated experimental room before and after the avoidance session. In fact, pilot experiments had shown a low avoidance performance in some of the test conditions, particularly when a light CS was combined with intertrial response punishment. This could have been due, at least in part, to a response bias created by the lower activity level in the light than in the dark portion of the cycle.

\section{Results}

Experiment 1A. ANOVAs, performed separately for each week, with three grouping factors and one repeated measures factor (Jennrich \& Sampson, 1979), showed that the mice (Figure 1) acquired avoidance more slowly with the light than with the buzzer CS $[1$ st week, $F(1,64)=$ 73.47, $\mathrm{p}<.001 ;$ 2nd week, $\mathrm{F}(1,64)=60.86$, $\mathrm{p}<.001$ ]. Intertrial response punishment also exerted an overall retarding effect $[1$ st week, $F(1,64)=9.99$, $\mathrm{p}<.0025 ;$ 2nd week, $\mathrm{F}(1,64)=13.33$, $\mathrm{p}<.001]$. However, groups trained with the buzzer CS were less sensitive to the depressant effect of intertrial response punishment, particularly in the 2nd week [CS $\times$ intertrial condition, $\mathrm{F}(1,64)=4.45, \mathrm{p}<.05]$.

The differences in trends in successive days of the 1 st week were confirmed by significant interactions between CS modality and sessions $[\mathrm{F}(4,256)=10.11, \mathrm{p}<.001]$ and between intertrial condition and sessions $[F(4,256)$ $=2.73, \mathrm{p}<.05]$. On the other hand, partition effects were generally not large and rather selective. During the 1 st week, the depressant influence of intertrial response punishment was more marked without than with the partition in buzzer-CS animals, but not in light-CS animals [CS $\times$ partition $\times$ sessions, $F(4,256)=2.71, p<.05]$. Among the groups with light CS, only the one run without intertrial response punishment and without the partition showed substantial increments in the 2 nd week, ending up at a final level similar to that of the buzzer groups [interaction between all four factors, $F(4,256)=3.93$, $\mathrm{p}<.005]$.

Intertrial crossings (Figure 1, lower graphs; see legend for the adjustments used to make the rates comparable to those of avoidance) were significantly reduced by the presence of the partition, by punishment of intertrial responses, and by the noise CS (main effects and/or their interactions with sessions were all significant in both weeks; statistical details omitted for brevity). The enhancing effects of absence of intertrial response punishment and absence of partition were more than additive [partition $X$ intertrial condition, $F(1,64)=6.94, p<.025]$.

Experiment 1B. This experiment (Figure 2) confirmed the differences in avoidance acquisition due to type of CS and to intertrial condition (main effects highly significant in both weeks). However, avoidance acquisition was somewhat facilitated by punishment of intertrial responses in the buzzer groups, particularly the group exposed to the higher shock level [CS $\times$ intertrial condition-1st week, $F(1,88)=5.68, \mathrm{p}<.025 ;$ 2nd week, $\mathrm{F}(1,88)=$ $5.75, p<.025]$. Although light CS groups performed similarly at both shock intensities, the acquisition of buz- zer avoidance was impaired by reduction of the shock level [CS $\times$ intensity -1 st week, $F(1,88)=5.59, \mathrm{p}<.025$; CS $\times$ intensity $\times$ sessions -2 nd week, $F(4,352)=2.92$, $\mathrm{p}<.025]$.

Intertrial crossings were similar to those of Experiment $1 \mathrm{~A}$, showing significant reductions of activity due to intertrial response punishment and to the higher shock intensity. The effects of these two variables were more than additive, and substantial numbers of intertrial responses were measured only in the groups trained with a low shock intensity and without intertrial punishment [intensity $\times$ intertrial condition-1st week, $F(1,88)=$ $8.38, \mathrm{p}<.005 ;$ 2nd week, $\mathrm{F}(1,88)=9.75, \mathrm{p}<.0025$ when comparing these data with those of Figure 1 one should remember that all groups in Experiment 1B were trained with a partition]. In the absence of intertrial response punishment, intertrial crossings were more frequent in the light-CS groups than in the buzzer-CS groups. This difference, however, reached statistical significance only in the lst week $[C S \times$ sessions, $F(4,352)=3.90$, $\mathrm{p}<.005 ; \mathrm{CS} \times$ intertrial condition $\times$ sessions, $\mathrm{F}(4,352)$ $=2.60, \mathrm{p}<.05]$.

Experiment 1C. This experiment confirmed the absence of shock-intensity effects on light-cued avoidance and the retarding influence of intertrial response punishment.

\section{Discussion}

In an order of increasing complexity, the results of Experiments $1 \mathrm{~A}-1 \mathrm{C}$ can be summarized as follows. Although the buzzer was a much more effective CS than light, the frequency of intertrial crossings tended to be lower with the former than with the latter signal. In the groups trained with the light CS, intertrial response punishment retarded avoidance acquisition and reduced the frequency of intertrial crossings to very low levels. The effects of the intertrial contingency, however, were more variable in the case of the buzzer CS, sometimes resulting in superior performance in the presence of intertrial response punishment. Shock level did not affect light-cued avoidance, but buzzer groups performed somewhat better with $1.5-\mathrm{mA}$ than with $.35-\mathrm{mA}$ shock. Moreover, intertrial crossings were more frequent at the lower than at the higher intensity level, which indicates that the effects of the intensity variable on activity and avoidance were dissociated from one another. Finally, the effects of the apparatus factor (presence vs. absence of the central partition) were limited and rather selective; for example, the absence of both partition and intertrial response punishment allowed one of the light-CS groups to reach a final avoidance level substantially higher than the levels reached by the other groups trained with the same signal. To some extent, the effects of this variable on avoidance and activity were also dissociated from one another, since most groups trained without the partition showed an elevation of intertrial crossings (for further analysis of partition effects, see Discussion in Experiment 3 and General Discussion below). 
INTERTRIAL
RESPONSES $\begin{cases}\bullet & \bullet \text { PUNISHED } \\ \Delta & \text { NOT PUNISHED }\end{cases}$

PARTITION $\left\{\begin{array}{l}--- \text { NO } \\ - \text { YES }\end{array}\right.$

NON-DIRECTIONAL CS

BUZZER LIGHT
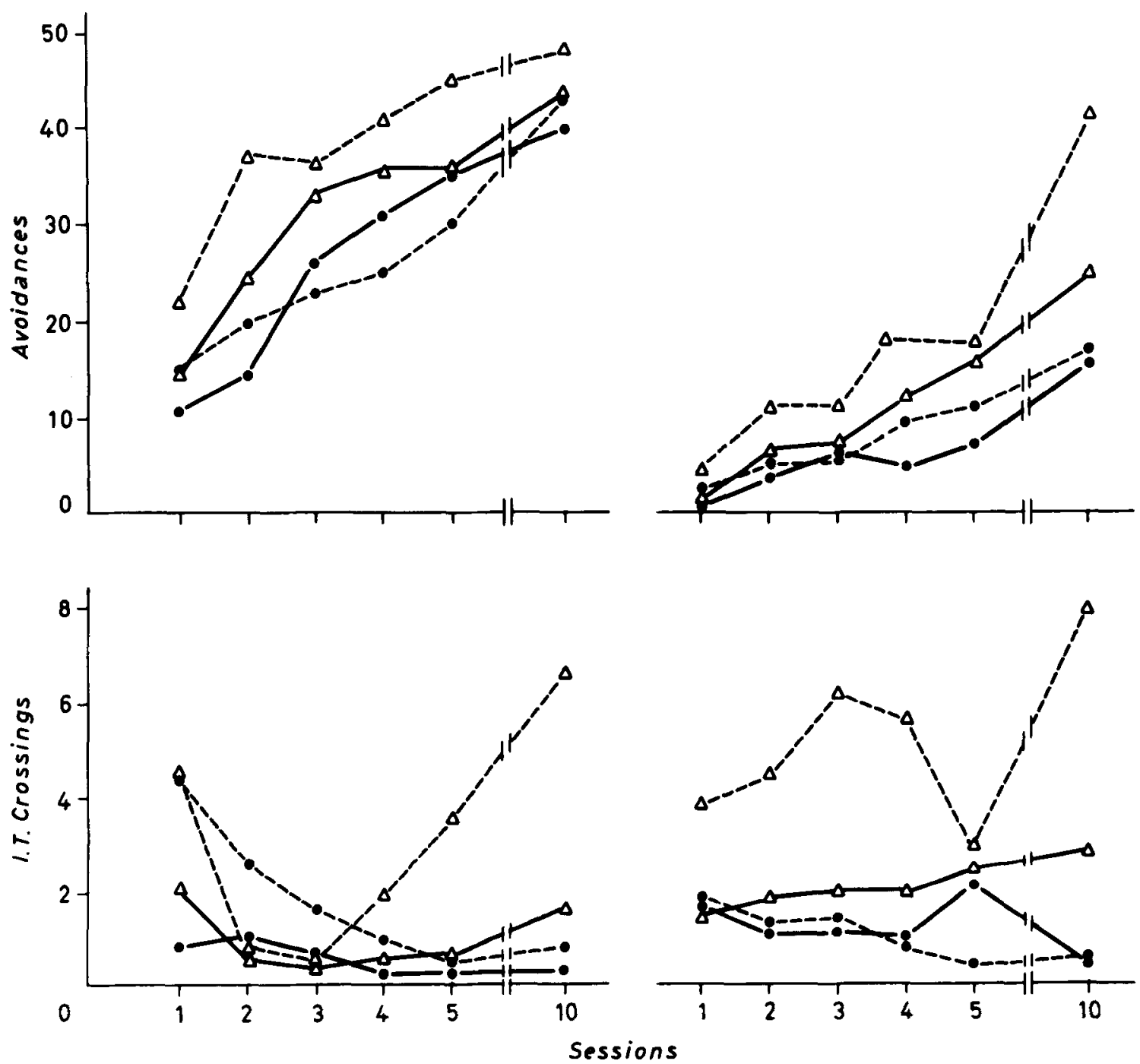

Figure 1. Avoidance acquisition by mice trained, in Experiment 1A, with either a buzzer or a light CS (both nondirectional), with or without punishment of intertrial (I.T.) crossings, and with or without a central partition in the shuttlebox (all groups with 1.5-mA shock and 30-sec CS-CS intervals). The frequency of I.T. crossings is adjusted to allow direct comparison with that of avoidences, both by subtracting forced recrossings by animals punished for intertrial responding and by taking into account intertrial interval duration relative to CS-US interval duration. Avoidance acquisition was faster with the bumer than with the light CS and faster in the absence than in the presence of intertrial response punishment. The groups trained without the partition showed a slight facilitation, except when the buzzer CS was combined with intertrial response punishment.

How do these mice data compare with the effects previously reported with rats? Effects of intertrial contingencies and CS modality were generally similar. Specifically, a buzzer was an effective avoidance signal even in conditions producing a marked suppression of intertrial responses. Of course, an understanding of CS modality effects also requires extensive information on unconditioned, pseudoconditioned, and classically conditioned responses to various types of stimuli (see, e.g., Izquierdo \& Cavalheiro, 1976; Jacobs \& LoLordo, 1980; Katzev \& Mills, 1974; Myers, 1960, 1965; Oliverio, 1968; Sigmundi \& Bolles, 1983; for the aversive properties of acoustic stimuli on mice, see Baron \& Kish, 1962).

The effects of shock level and of the apparatus factor differed from those observed in rats. This is especially striking because these variables affected intertrial respond- 


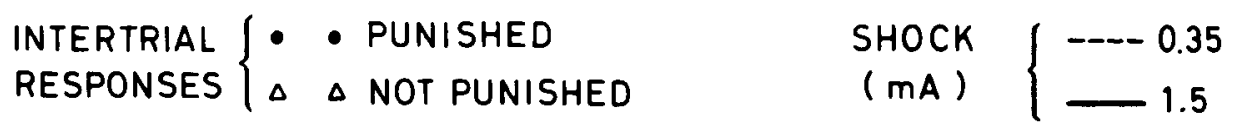

NON-DIRECTIONAL CS
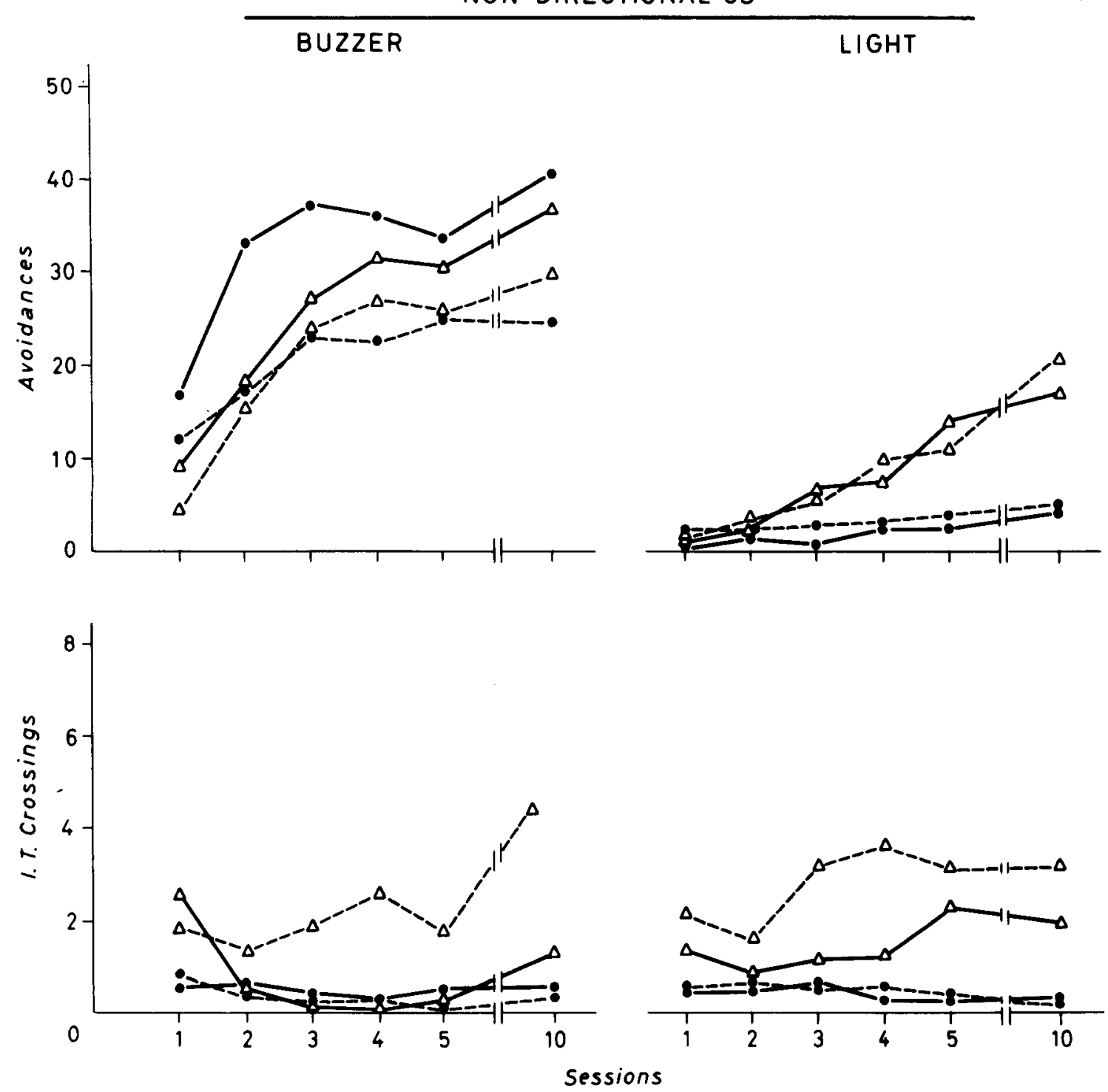

Figure 2. Avoidance acquisition by mice trained, in Experiment 1B, with either a buzzer or a light CS (both nondirectional), with or without punishment of intertrial (I.T.) crossings, and either a low or a high shock level (all groups with the partition and 30-sec CS-CS intervals). Animals trained with the buzzer CS showed some impairment at the lower shock level, but light CS groups performed similarly at both intensities. By contrast, the lower shock level produced an increase of overall activity in the absence of intertrial response punishment (for rate adjustments see caption for Figure 1). Experiment 1C (not reported in detail) showed no effects of four different shock levels $(.35, .6,1$, and $1.5 \mathrm{~mA})$ on light-cued avoidance.

ing in the direction suggested by rat experiments; for example, crossings were reduced to practically zero whenever a high intensity and a partition were combined with intertrial response punishment. Higher intensities than those used here might depress mouse bidirectional avoidance. However, the $1.5-\mathrm{mA}$ level was more than four times above that which sufficed to produce reliable escape. In addition, all mice trained with 1.5-mA shock initially showed many signs of distress, such as loud squealing, wild running, and jumping. At a comparable punishment level, all experiments with rats have shown a depression of bidirectional avoidance, except in the case of manipulations aimed specifically at a reduction of fear conditioning to general apparatus cues (see particularly Dieter, 1977, and McAllister et al., 1979). In this way, bidirectional noise-cued avoidance in mice resembles one-way, 
rather than two-way, avoidance in rats, reminiscent of the modified bidirectional tasks in which the adverse influence of a high shock intensity is eliminated (Modaresi, 1975).

\section{EXPERIMENT 2}

Rats tend to avoid brightly illuminated places (see review by Hill, 1978, p. 1179), and their preference for dark or dimly illuminated places is markedly enhanced when they are frightened (Allison, Larson, \& Jensen, 1967; see also the discussion by Seligman \& Hager, 1972; Welker \& Wheatley, 1977). This may explain why acquisition of avoidance tasks is often impaired when a rat is required to move toward light, or to use as the CS a nondirectional "light-off"' signal (with light turned on again by the appropriate response), or to come close to a source of light in order to operate a manipulandum (Biederman, D'Amato, \& Keller, 1964; Bignami \& De Acetis, 1973; Bignami \& Rosić, 1972; Bucci \& Bovet, 1974; Kelsey \& Grossman, 1969; Whittleton et al., 1965).

However, avoidance impairments have also been observed with a "noise-off' CS and when rats were required to move toward the source of the acoustic signal (Hurwitz \& Dillow, 1968; Myers, 1960; Whittleton et al., 1965). Therefore, it has been suggested that independently of the "away-versus-toward" or the "on-versus-off" CSresponse contingency, any signal presented in a punishment context becomes aversive, leading to its avoidance (Whittleton et al., 1965). Classical fear conditioning to either an acoustic or a visual signal develops more promptly with increases than with decreases of the baseline stimulus intensity (Welker \& Wheatley, 1977; Zieliniski, 1965), and 'tone off' and "light off' exerted conditioned inhibitory, but no conditioned excitatory, control (Jacobs \& LoLordo, 1980). Under the conditions used by these investigators, "light on" was also unable to exert excitatory control. By contrast, a considerable amount of work, including that on "light-on/light-off" comparisons mentioned above, shows that "light on" can be an effective avoidance CS (see, e.g., Bignami et al., 1971; Cicala \& Azorlosa, 1984; Giardini, Amorico, De Acetis, \& Bignami, 1983).

One experiment failed to show differences in two-way avoidance acquisition in an inbred strain of mice trained either with an "away-from-light" or a "toward-light" contingency (Oliverio, 1968). The seeming contrast between mouse and rat data spurred us to investigate the effects of opposite types of directional CS. Moreover, the explanations offered for the impairment of rat avoidance by a "light-off"' CS provided the impetus for a study of the effects of the CS variable in different punishment conditions. Accordingly, the two types of CS were combined with either presence or absence of intertrial response punishment and with either a low or a high shock level.

\section{Method}

Subjects, apparatus, and most procedures were as in Experiment 1 . Eleven mice were assigned to each of eight conditions (see
Table 1) with .35- or 1.5-mA shock, presence or absence of intertrial response punishment, and a directional CS consisting of onset of illumination either in the compartment in which a trial was started or in the opposite compartment (all groups run with the central partition). The training period was extended to 3 weeks (15 sessions) due to the low avoidance level shown by most groups at the end of the 2 nd week.

\section{Results}

Low avoidance performances occurred in the first 2 weeks of the experiment (Figure 3). Effects of the CS factor were negligible and not statistically significant. The lower shock intensity exerted a small facilitating influence in the 1st week, which disappeared in the 2nd week and was reversed at the end of training. An ANOVA using three blocks of five sessions each showed the intensity $x$ blocks interaction to be significant $[F(2,160)=6.85$, $p<.0025]$. A progressive increase in the frequency of intertrial crosssings occurred in the groups without intertrial punishment, particularly in those exposed to the lower shock intensity [intertrial condition $x$ shock intensity $x$ blocks, $F(2,160)=4.67, p<.025]$. Differences in activity due to type of CS in animals trained with a high shock intensity and without intertrial response punishment were not significant.

\section{Discussion}

The data confirm that mice perform similarly in a twoway avoidance task when required to move away from light or toward light (Oliverio, 1968). The present experiment extends this finding to test conditions that produce marked differences in rate of acquisition, due mainly to presence or absence of a passive avoidance contingency during intertrial intervals.

These results suggest that mice, unlike rats, are not prepared to use light and darkness as danger and safety signals, respectively. This difference may be related to the fact that mice, although more active during the night, show repeated bouts of activity, feeding, and drinking in the lighted portion of the $24-\mathrm{h}$ cycle as well, whereas rats show a near-complete diurnal inactivity. These activity patterns may, in turn, be related to metabolic requirements which differ as a function of body size.

There was an initial facilitation of avoidance at the lower shock level and an opposite effect in later stages of training. These effects were small, when compared with those found in rats over the same intensity range (for data obtained in the same laboratory and with the same apparatus, except for the different size of the shuttleboxes used in two species, see Bignami et al., 1971). Moreover, acquisition was quite slow even by light-CS standards (see specifically the groups in Experiments $1 \mathrm{~A}$ and $3 \mathrm{~B}$ that were trained with $1.5-\mathrm{mA}$ shock, no intertrial response punishment, the partition, a 30-sec CS-CS interval, and a maximal duration of shock of $10 \mathrm{sec}$ ), which may have made more apparent the slight facilitatory influence of the milder shock. Overall, the data confirm that, in mice, the effects of shock intensity level on two-way avoidance are absent (light CS groups in Experiments 1B-1C), small 


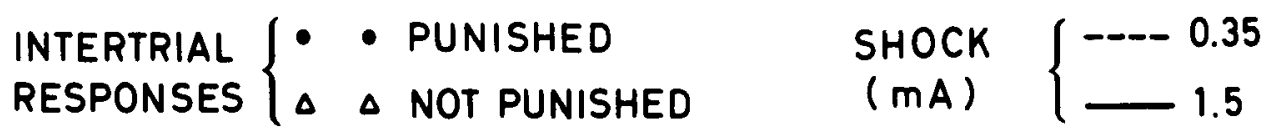

LIGHT ON CS (DIRECTIONAL)

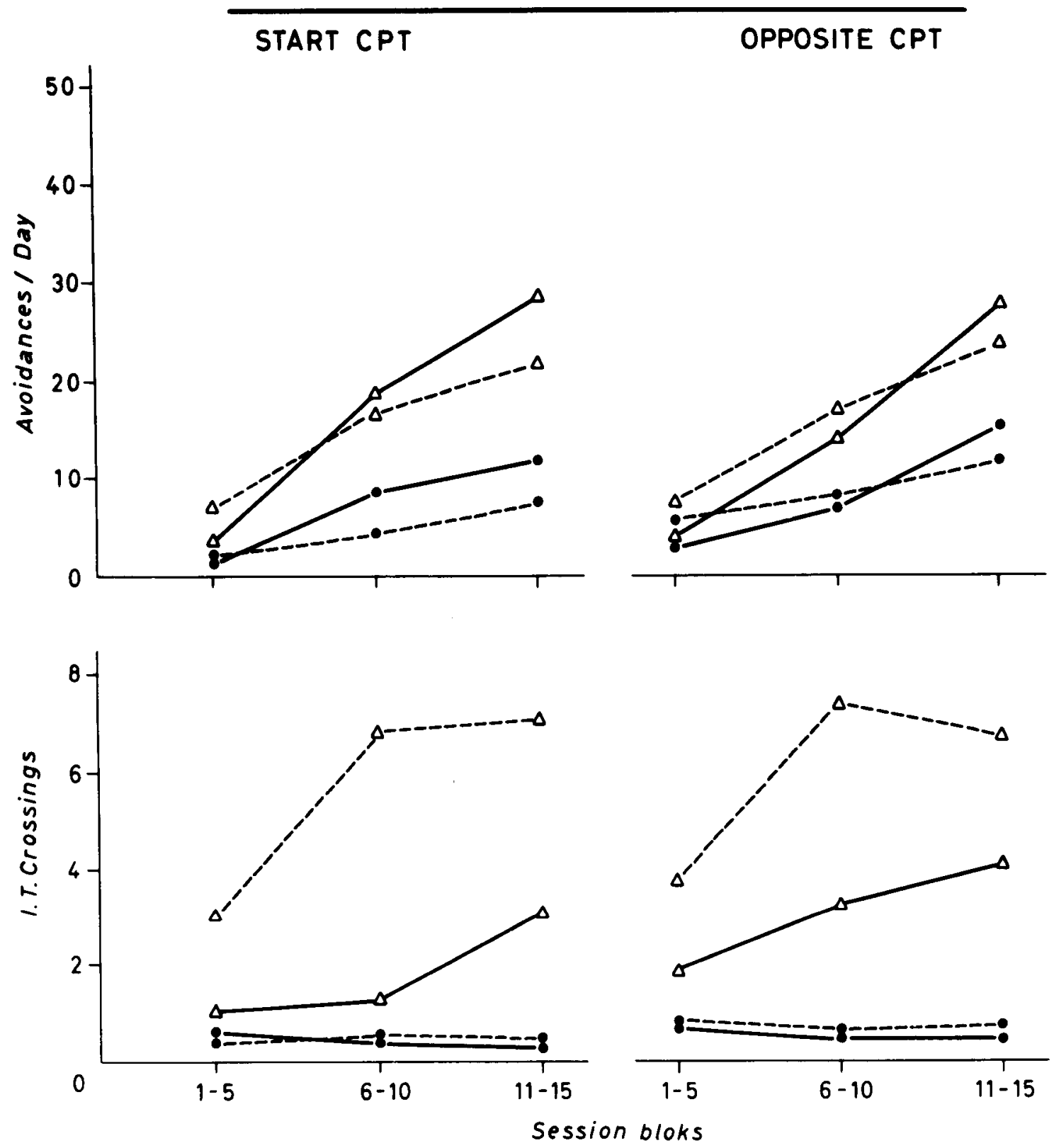

Figure 3. Avoidance acquisition by mice trained, in Experiment 2, with opposite types of directional light CSs (start compartment = go away from light; opposite compartment = go toward light), a high or a low shock level, and with or without punishment of intertrial (I.T.) crossings (all groups with the partition and 30-sec CS-CS intervals). The data are presented as blocks of five sessions each, since the experiment was extended to 3 weeks of training because of slow acquisition and low performance levels at the end of the 2 nd week. Acquisition rate was not affected by type of CS. The lower shock intensity produced a slight initial facilitation, which was reversed in the later stages of training, and an increase of I.T. crossings in the absence of intertrial response punishment (for rate adjustments, see caption for Figure 1). 
(present experiment), or in a direction opposite to that expected on the basis of rat data (buzzer groups in Experiment 1B).

\section{EXPERIMENT 3A-3B}

Bidirectional rat avoidance is markedly affected by the duration of intertrial intervals. Brief intervals, which produce high initial shock densities, lead to slower acquisition than do longer intervals. Proposed explanations include response competition and reinforcement models (Archer et al., 1984; Bignami et al., 1971; Bolles \& Grossen, 1970; Brush, 1962; Denny, Zerbolio, \& Weisman, 1969; Kurtz \& Shafer, 1967; Levine \& England, 1960; McAllister et al., 1971; Murphy \& Miller, 1956).

An effect of intertrial interval has been reported in mice (Bovet, Bovet-Nitti, \& Oliverio, 1968). However, Experiment 1 , which used a short CS-CS interval $(30 \mathrm{sec}$ ), yielded slow rates of acquisition in groups trained with the light CS, but not in those trained with a buzzer CS. Therefore, the present experiment used light-cued avoidance to analyze possible interactions between the interval variable and some other selected variables.

CS-CS intervals of 30 and $60 \mathrm{sec}$ were used. Since Experiments $1 \mathrm{~A}-1 \mathrm{C}$ had used only nondirectional signals and Experiment 2 had failed to show an influence by opposite arrangements of a directional signal, Experiment $3 \mathrm{~A}$ compared directly a directional and a nondirectional signal. Experiment 3B examined the effects of CS-CS interval and of other variables that can affect the amount of shock received in the early stages of training. The maximal duration of a high-intensity shock was varied $(5 \mathrm{vs} .10 \mathrm{sec})$, and the animals were trained either with or without a partition.

\section{Method}

The subjects, apparatus, and most of the procedures were as in the previous experiments. In Experiment 3A, which lasted 2 weeks (10 sessions), all animals were run with the central partition in place, with a shock intensity of $1.5 \mathrm{~mA}$, and without punishment of intertrial crossings (see Table 1). Twelve mice were assigned to each of four conditions, using two durations of the CS-CS interval (30 vs. $60 \mathrm{sec}$ ) and either a directional or a nondirectional light on CS. In Experiment 3B, all animals were run with a 1.5-mA shock intensity, no punishment of intertrial crossings, and a nondirectional light-on CS. Ten mice were assigned to each of eight conditions, with 30- or 60-sec CS-CS intervals, presence or absence of the central partition, and either 5 or $10 \mathrm{sec}$ of maximal shock duration in case of escape delay or failure (see Table 1). In this part of the experiment, training lasted five sessions.

\section{Results}

Experiment 3A. Data from the 1st week of training are reported in Figure 4. Data from the 2nd week did not provide additional information on between-group differences. The CS variable had no effects on intertrial responses, and the longer CS-CS interval increased the crossing rate only slightly.

A 60 -sec interval yielded faster avoidance acquisition than did the 30-sec interval $[F(1,64)=45.97, p<.001]$.

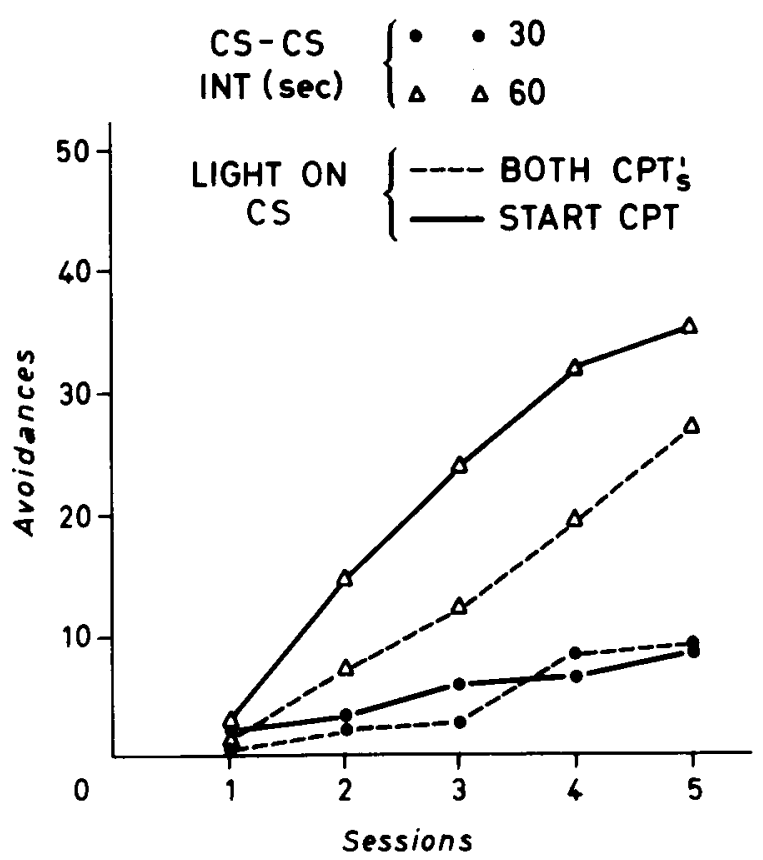

Figure 4. Avoidance acquisition by mice trained, in Experiment 3A, with different CS-CS interval durations and either a directional or a nondirectional light on CS (all groups with the partition, 1.5-mA shock, and no punishment of intertrial crossings; see text for 2nd-week data and intertrial response data omitted from the figure). Doubling of the CS-CS interval exerted on overall facilitating effect, whereas a directional signal accelerated avoidance acquisition only in animals trained with the longer CS-CS interval.

The directional CS further facilitated avoidance in mice trained with the longer interval. In contrast, the rates of acquisition were equally low with both a directional and a nondirectional signal in the groups trained with the shorter interval [CS $\times$ interval, $F(1,44)=4.35$, $\mathrm{p}<.05]$.

Experiment 3B. The results (Figure 5) confirmed the overall superiority of the groups trained with the $60-\mathrm{sec}$ CS-CS interval $[\mathrm{F}(1,72)=7.39, \mathrm{p}<.01]$. However, as training progressed, the deficit due to the briefness of the CS-CS interval attenuated in the groups trained without the partition, particularly when the maximal shock duration was reduced [partition $x$ interval $\times$ sessions, $F(4,288)=4.47, p<.0025$; partition $\times$ maximal shock duration $\times$ sessions, $F(4,288)=4.05, p<.005$; only the two groups trained with the partition and a $10-\mathrm{sec}$ maximal shock duration are comparable to the groups in Experiment $3 A$ trained with a nondirectional CS]. The second interaction confirms that a brief shock duration facilitated avoidance in the absence of a partition, but impaired avoidance in its presence. The only substantial effect on intertrial responses was a higher rate of crossings in the groups trained without the partition.

\section{Discussion}

The results of this experiment confirm that various CS, US, and apparatus variables interact to produce different "coping styles." Mice, like rats, showed considerable 


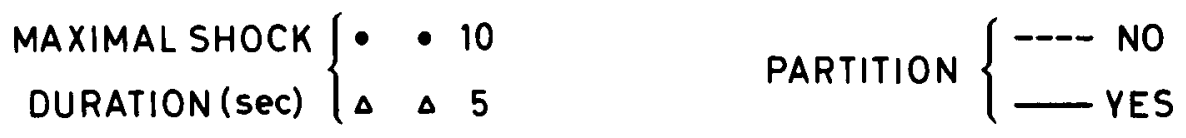

\section{CS-CS INTERVAL (sec)}

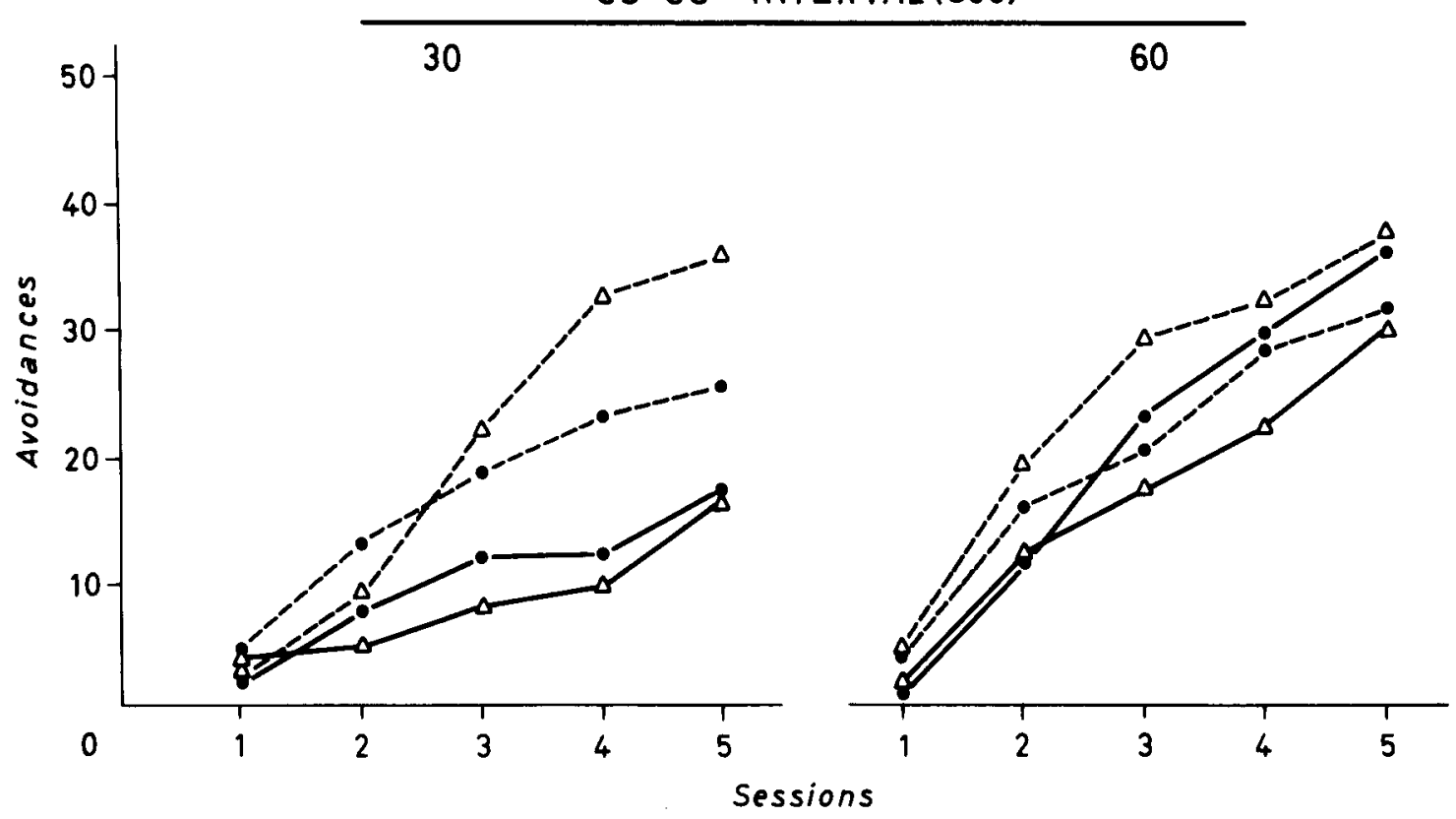

Figure 5. Avoidance acquisition by mice trained, in Experiment 3B, with different CS-CS interval durations, different maximal durations of shock in case of escape delay or failure, and presence or absence of the partition in the shuttlebox (all groups received a nondirectional light CS, 1.5-mA shock, and no intertrial response punishment). Besides replicating the facilitation by the longer CS-CS interval (Experiment 3A), the data show a facilitation by the shorter shock duration limited to animals trained without the partition. For intertrial response data omitted from the figure, see text.

avoidance facilitation when faced with a lower initial shock density. Moreover, the animals trained with the longer CS-CS interval, but not those trained with the shorter interval, exploited the directional light signal, achieving a rate of acquisition and a final performance that was much higher than those of most light groups.

Mice trained in conditions that usually produce poor avoidance (a light CS and a high initial shock density) were facilitated by apparatus and US contingencies aimed at reducing initial shock exposure (the absence of a partition and a short duration of maximal shock). By contrast, mice that were required to find their way through an opening of limited size were not only not helped, but were even impaired, by a reduction of maximal shock duration.

Due to the lack of systematic data on response latencies and escape failures, considerable caution is needed in interpreting the latter effects, particularly since such failures never occurred in substantial numbers in any of the groups. Limited observations in a subsidiary experiment showed that mice, when initially exposed to shock, cross less readily to the opposite side of the box in the presence of a partition than in its absence. The interaction between this variable and the shock duration variable suggests that adequate experiments can further separate the two opposite effects of extended shock exposure in the case of initial escape delays. In fact, as is well known, prolonged punishment tends to reduce activity in subse- quent no-shock periods. Under particular conditions, however, this effect may be obscured by the fact that additional shock serves to complete the appropriate response, which is a necessary prerequisite for subsequent avoidance acquisition.

\section{GENERAL DISCUSSION}

Useful information on the mechanisms underlying behavior regulation can be obtained by comparing the responses of related species to manipulation of a number of critical test variables. Mouse avoidance data allow the separation of two phenomena, the effects of shock density and shock intensity. Differences between mice and rats may occur because a smaller body size may allow faster initial acceleration on exposure to shock. This may explain the relative insensitivity of mouse bidirectional avoidance to strong punishment. In contrast, shock density is a variable fixed by the experimenter, although the duration of each shock depends on the speed of the escape response. Therefore, it is not surprising that mice and rats respond similarly to manipulations of intertrial interval length.

The overall effects of stimulus modality appear to be similar in rats and mice, although only rats show marked differences due to the "away from light" versus "toward 
light" contingency (for a tentative explanation see Discussion of Experiment 2). More generally, noise signals tend to be highly effective in different species, different tests, and different versions of the same test. By contrast, light CS can produce the whole range of avoidance abilities, from no learning to fast learning, depending both on species and on conditions within a given test. Therefore, the controversy regarding the relative effectiveness of acoustic and visual cues as active avoidance CS, using rat data (Cicala \& Azorlosa, 1984; Jacobs \& LoLordo, 1977,1980 ), may reflect the limited range of test conditions employed in any given experiment.

These comparisons between the results obtained in different species may be biased by the fact that the present experiments were performed during the dark portion of the cycle (for a rationale, see Procedure in Experiments $1 \mathrm{~A}-1 \mathrm{C})$. As already emphasized, however, some of the data were in agreement with those of previous mouse experiments carried out in other laboratories. Moreover, it appears unlikely that the effects of time of testing can be selective to the point of producing both substantial analogies and marked differences between mouse and rat avoidance, depending on the particular variable or combination of variables.

The data so far discussed suggest that the role of organismic variables is often overemphasized, due to the difficulty in understanding interactions between test variables. For example, several investigators have emphasized the dramatic effects of bidirectional genetic selection on rat avoidance (e.g., Bignami, 1965), or the marked differences in avoidance between mice of various inbred strains, rather than explaining why an animal of a particular strain can be either an excellent or a very poor learner in what may superficially appear to be slightly different versions of the same task.

A final point concerns the relative capacity of alternative avoidance models to explain the mouse data. Differences in "coping styles" produced by the joint influence of several test variables could confirm (or disconfirm) any of the available models. Buzzer avoidance is acquired without difficulty, even under the most unfavorable conditions (e.g., when a high initial shock density, punishment of intertrial crossings, and a partition are combined). Apparently, only an organismic process such as that proposed by Bolles (1970) can cope with this type of data.

However, the effects of other variables on avoidance are more easily explained by one or the other version of the reinforcement model (see, particularly, the discussion by Jacobs \& LoLordo, 1980). This applies, for example, to avoidance facilitation by a directional light CS only in mice trained with an extended CS-CS interval: this cannot be explained by a greater readiness of shocked mice to move toward dark rather than toward light. Moreover, if place discriminability were responsible for the observed differences, a facilitation by the directional signal would have been obtained at both CS-CS interval durations. A reinforcement model can account for the fact that (after attenuation of fear conditioning to apparatus cues by the lowering of shock density) the reinforcing values of stimulus situations associated with danger and safety can be enhanced by a directional quality of the available signal.

Other models offer little to explain the present data. Explanations based mainly on reduction of shock density by the animal's response (Herrnstein, 1969; Herrnstein \& Hineline, 1966) predict better performance at high shock densities, at least in the absence of intertrial response punishment. This prediction is correct in the case of tasks using manipulatory responses (see particularly the discussions in Morris, 1974, and Rakover, 1980), but the data on bidirectional locomotor avoidance are the opposite.

The wide range of complementary processes unveiled by fine-grain analyses of avoidance results does not appear to be amenable to explanation by any single model. This inference is not new, as indicated, for example, by the fact that 20 years ago people were working in the same laboratory to show both that avoidance response feedbacks acquired conditioned inhibitory control (Soltysik \& Kowalska, 1960; Konorski, 1967) and that short-latency avoidance responses could not be explained by two-factor models (Zieliński, 1966, 1972). In recent years, both reinforcement and preparedness models have been modified to account for an increasing body of complex data (Bolles, 1978; Crawford \& Masterson, 1982; Jacobs \& LoLordo, 1980 ). As shown by the present and related work, an analysis of the phenomena revealed by experiments with different species can contribute to our understanding of the differences in "coping styles" that depend on organismic and test variables.

\section{REFERENCES}

Alleva, E., De Acetis, L., Amorico, L., \& Bignami, G. (1983). Amphetamine, conditioned stimulus, and nondebilitating preshock effects on activity and avoidance: Further evidence for interactions between associative and nonassociative changes. Behavioral \& Neural Biology, 39, 78-104.

Allison, J., Larson, D., \& Jensen, D. D. (1967). Acquired fear, brightness preference, and one-way shuttlebox performance. Psychopharmacology, 8, 269-270.

Anisman, H., \& Waller, T. G. (1972). Facilitative and disruptive effects of prior exposure to shock on subsequent avoidance performance. Journal of Comparative \& Physiological Psychology, 78, 113-122.

ArCher, T., OGren, S.-O., Johansson, G. (1984). Stimulus conditions affecting rate of acquisition in a computer-operated version of the two-way active avoidance procedure. Scandinavian Journal of Psychology, 25, 89-95.

Ashe, V. M., MCCAIN, G. (1972). Comparison of one-way and shuttle-avoidance performance of gerbils and rats. Journal of Comparative \& Physiological Psychology, 80, 293-296.

BARON, A., KISH, G. B. (1962). Low-intensity auditory and visual stimuli as reinforcers for the mouse. Joumal of Comparative \& Physiological Psychology, 55, 1011-1013.

Bauer, R. H. (1972). The effects of CS and US intensity on shuttlebox avoidance. Psychonomic Science, 27, 266-268.

Biederman, G. B. (1967). Discriminated avoidance conditioning: Stimulus function in shaping and training. Psychonomic Science, 9, 263-264.

Biederman, G. B., D'Amato, M. R., \& Keller, D. M. (1964). Facilitation of discriminated avoidance learning by dissociation of CS and manipulandum. Psychonomic Science, 1, 229-230.

BIGNAMI, G. (1965). Selection for high rates and low rates of avoidance conditioning in the rat. Animal Behaviour, 13, 221-227. 
Bignami, G., Amorico, L., Frontali, M., \& Rosić, N. (1971). Central cholinergic blockade and two-way avoidance acquisition: The role of response disinhibition. Physiology \& Behavior, 7, 461-470.

Bignami, G., \& DE ACETIS, L. (1973). An investigation on the nature of continuous avoidance deficits: Differential response to chlordiazepoxide treatment. Pharmacology Biochemistry \& Behavior, 1, 277-283.

BIGNAMI, G., \& Rosić, N. (1972). Acquisition and performance effects of scopolamine and of treatment withdrawal in avoidance situations. Physiology \& Behavior, 8, 1127-1134.

Bolles, R. C. (1970). Species-specific defense reactions and avoidance learning. Psychological Review, 77, 32-48.

BoLles, R. C. (1978). The role of stimulus learning in defensive behavior. In S. H. Hulse, H. Fowler, \& W. K. Honig (Eds.), Cognitive processes in animal behavior. Hillsdale, $\mathrm{NJ}$ : Erlbaum.

Bolles, R. C., \& Grossen, N. E. (1970). Function of the CS in shuttlebox avoidance learning by rats. Journal of Comparative \& Physiological Psychology, 70, 165-169.

Bolles, R. C., Hargraye, G. E., \& Grossen, N. E. (1970). Avoidance learning as a function of CS quality and CS termination on escape trials. Psychological Reports, 26, 27-32.

Bovet, D., Bovet-NitTi, F., \& OLIVErIo, A. (1968). Memory and consolidation mechanisms in avoidance learning of inbred mice. Brain Research, 10, 168-182.

Brush, F. R. (1962). The effects of intertrial interval on avoidance learning in the rat. Journal of Comparative \& Physiological Psychology, $55,888-892$.

Buccl, L., \& BoveT, D. (1974). The effect of iproniazid and tranylcypromine studied with a dark-avoidance conditioned schedule. Psychopharmacology, 35, 179-188.

Carran, A. B., Yeudall, L. T., \& Royce, J. R. (1964). Voltage level and skin resistance in avoidance conditioning of inbred strains of mice. Journal of Comparative \& Physiological Psychology, 58, 427-430.

Cicala, G. A., \& Azorlosa, J. L. (1984). Light is an effective warning signal in avoidance learning. Bulletin of the Psychonomic Society, 32, 70-72.

Cicala, G. A., OWEn, J. W., \& Hill, D. (1976). Successful shuttle avoidance learning with high-intensity USs is sustained if a feedback signal accompanies warning-signal termination. Bulletin of the Psychonomic Society, 7, 533-535.

Crawford, M., \& Masterson, F. A. (1982). Species-specific defense reactions and avoidance learning. An evaluative review. The Pavlovian Journal of Biological Science, 17, 204-214

Dalby, D. A., \& Shuttlesworth, D. E. (1978). Effect of septal lesions, required response, and shock on the acquisition of a two-way conditioned avoidance response in rats. Physiological Psychology, 6 11-14.

Denny, M. R., Zerbolio, D. J., JR., Weisman, R. G. (1969), Avoidance learning in heterogeneous and homogeneous shuttle boxes. Journal of Comparative \& Physiological Psychology, 68, 370-372.

Dieter, S. E. (1977). Preexposure to situational cues and shock intensity in two-way avoidance learning. Animal Learning \& Behavior, $5,403-406$.

Frontali, M., \& Bignami, G. (1973) Go-no go avoidance discriminations in rats with simple "go" and compound "no go" signals: Stimulus modality and stimulus intensity. Animal Learning \& Behavior, 1 , 21-24.

Frontali, M., Bignami, G. (1974). Stimulus nonequivalences in go/no-go avoidance discriminations: Sensory, drive, and response factors. Animal Learning \& Behavior, 2, 153-160.

Galvani, P. F., Riddell, W. I., \& Foster, K. M. (1975). Passive avoidance in rats and gerbils as a function of species-specific exploratory tendencies. Behavioral Biology, 13, 277-290.

Giardini, V., Amorico, L., De Acetis, L., \& Bignami, G. (1983). Scopolamine and acquisition of go-no go avoidance: A further analysis of the perseverative antimuscarinic deficit. Psychopharmacology, 80, 131-137.

Henderson, N. D. (1970). Motivation-performance relationships using different shock-avoidance shuttlebox techniques. Psychonomic Science, 21, 314-315.
HeRRNSTEIN, R. J. (1969). Method and theory in the study of avoidance. Psychological Reviw, 76, 49-69.

Herrnstein, R. J., \& Hineline, P. N. (1966). Negative reinforcement as shock-frequency reduction. Journal of Experimental Analysis of Behavior, 9, 421-430.

HILL, W. F. (1978). Effects of mere exposure on preferences in nonhuman mammals. Psychological Bulletin, 85, 1177-1198.

Hurwitz, H. M. B., \& Dillow, P. V. (1968). The effects of the warning signal on response characteristics in avoidance learning. Psychological Record, 18, 351-360.

IzQuierdo, I., Cavalheiro, E. A. (1976). Three main factors in rat shuttle behavior: Their pharmacology and sequential entry in operation during a two-way avoidance session. Psychopharmacology, 49, 145-157.

JACOBS, W. J., \& LoLoRDO, V. M. (1977). The sensory basis of avoidance responding in the rat. Relative dominance of auditory or visual warning signals and safety signals. Learning \& Motivation, 8 , 448-466.

JACOBS, W. J., \& LoLordo, V. M. (1980). Constraints on Pavlovian aversive conditioning: Implications for avoidance learning in the rat. Learning \& Motivation, 11, 427-455.

JenNRICH, R., \& SAMPSON, P. (1979). Analysis of variance and covariance including repeated measures. In W. J. Dixon \& M. B. Brown (Eds.), BMDP-79 biomedical computer programs. $P$ series (pp. 540580). Berkeley: University of California Press.

Johnson, J. L., \& ChURCH, R. M. (1965). Effects of shock intensity on nondiscriminative learning of rats in a shuttlebox. Psychonomic Science, 3, 497-498.

Katzev, R. D., \& MilLs, S. K. (1974). Classical conditioning of skeletal avoidance responses in two strains of rats. Psychological Reports, 35 , 355-360.

Kelsey, J. E., \& Grossman, S. P. (1969). Cholinergic blockade and lesions in the ventro-medial septum of the rat. Physiology \& Behavior, 4, 837-845.

KoNORSKI, J. (1967). Integrative activity of the brain. Chicago: University of Chicago Press.

KURTZ, P. S., \& SHAFER, J. N. (1967). The interaction of UCS intensity and intertrial interval in avoidance learning. Psychonomic Science, $8,465-466$.

LEVINE, S. (1966). UCS intensity and avoidance learning. Journal of Experimental Psychology, 71, 163-164.

LEVINE, S., \& ENGLAND, S. J. (1960). Temporal factors in avoidance learning. Journal of Comparative \& Physiological Psychology, 53, 282-283.

MCAllister, W. R., MCAllister, D. E., Dieter, S. E., \& JAMES, J. H. (1979). Preexposure to situational cues produces a direct relationship between two-way avoidance learning and shock intensity. Animal Learning \& Behavior, 7, 165-173.

MCAlLISTER, W. R., MCAlLISTER, D. E., \& DOUglass, W. K. (1971). The inverse relationship between shock intensity and shuttlebox avoidance learning in rats: A reinforcement explanation. Journal of Comparative \& Physiological Psychology, 74, 426-433.

MODARESI, H. A. (1975). One-way characteristic performance of rats under two-way signaled avoidance conditions. Learning \& Motivation, 6, 484-497.

Moot, S. A., Nelson, K., \& Bolles, R. C. (1974). Avoidance learning in a black and white shuttlebox. Bulletin of the Psychonomic Society, 4, 501-502.

MoRris, R. G. M. (1974). Two independent effects of variation in intertrial interval upon leverpress avoidance learning by rats. Animal Learning \& Behavior, 2, 189-192.

MOYER, K. E., KoRN, J. H. (1964). Effect of UCS intensity on the acquisition and extinction of an avoidance response. Jourmal of Experimental Psychology, 67, 352-359.

MURPHY, J. V., \& MiLLeR, R. E. (1956). Spaced and massed practice with a methodological consideration of avoidance conditioning. Joumal of Experimental Psychology, 52, 77-81.

MYERS, A. K. (1960). Onset vs. termination of stimulus energy as the $\mathrm{CS}$ in avoidance conditioning and pseudoconditioning. Joumal of Comparative \& Physiological Psychology, 53, 72-78. 
Myers, A. K. (1964). Discriminated operant avoidance learning in Wistar and G-4 rats as a function of type of warning stimulus. Journal of Comparative \& Physiological Psychology, 58, 453-455.

MYERS, A. K. (1965). Instrumental escape conditioning to a low-intensity noise by rats. Journal of Comparative \& Physiological Psychology, 60, 82-87.

MYERS, A. K. (1977). Shock intensity and warning signal effects on several measures of operant avoidance acquisition. Animal Learning \& Behavior, 5, 51-56.

OLIVERIO, A. (1967). Effects of different conditioning schedules based on visual and acoustic conditioned stimulus on avoidance learning of two strains of mice. Journal of Psychology, 65, 131-139.

Oliverio, A. (1968). Effects of scopolamine on avoidance conditioning and habituation of mice. Psychopharmacologia, 12, 214-226.

Osborne, G. L., Caul, W. F., \& Vanstrum, R. (1976). Avoidance differences between rats and gerbils. Animal Leaming \& Behavior, 4, 151-159.

Rakover, S. S. (1980). Role of intertrial interval following an escape or avoidance response in bar-press avoidance. Learning \& Motivation, 11, 220-237.

Rosić, N., Frontali, M., Bignami, G. (1969). Stimulus factors affecting go-no go avoidance discrimination learning by rats. Communications in Behavioral Biology, 4, 151-156.

Royce, J. R. (1966). Optimal stimulus parameters in avoidance conditioning of inbred strains of mice. Multivariate Behavioral Research, 1, 209-217.

SChINDler, C. W., \& WeISS, S. J. (1982). The influence of positive and negative reinforcement on selective attention in the rat. Learning \& Motivation, 13, 304-323.

Schwartzbaum, J. S., Greeen, R. H., Beatty, W. W., \& Thompson, J. B. (1967). Acquisition of avoidance behavior following septal lesions in the rat. Journal of Comparative \& Physiological Psychology, 63, 95-104.
Seligman, M. E. P., Hager, J. L. (1972). Biological boundaries of learning. New York: Appleton-Century-Crofts.

Sigmund, R. A., \& Bolles, R. C. (1983). CS modality, context conditioning, and conditioned freezing. Animal Learning \& Behavior, 11, 205-212.

SoltysiK, S., KowalsKa, M. (1960). Studies on the avoidance conditioning. I. Relations between cardiac (type I) and motor (type II) effects in the avoidance reflex. Acta Biologiae Experimentalis, 20, 157-170.

Theios, J., LyNCh, A. D., \& Lowe, W. F., JR. (1966). Differential effects of shock intensity on one-way and shuttle avoidance conditioning. Journal of Experimental Psychology, 72, 294-299.

Walters, G. C., ABEL, E. L. (1971). Passive avoidance learning in rats, mice, gerbils, and hamsters. Psychonomic Science, 22, 269-270.

Welker, R. L., \& Wheatley, K. L. (1977). Differential acquisition of conditioned suppression in rats with increased and decreased luminance levels as CS+s. Learning \& Motivation, 8, 247-262.

Whittleton, J. C., Kostanek, D. J., \& SAWrey, J. M. (1965). CS directionality and intensity in avoidance learning and extinction. Psychonomic Science, 3, 415-416.

ZIELIŃSKI, K. (1965). The direction of change versus the absolute level of noise intensity as cue in the CER situation. Acta Biologiae Experimentalis, 25, 337-357.

ZIELIŃSKI, K. (1966). Retention of the avoidance reflex after prefrontal lobectomy in cats. Acta Biologiae Experimentalis, 26, 167-181.

ZIELIŃSKI, K. (1972). Effects of prefrontal lesions on avoidance and escape reflexes. Acta Neurobiologiae Experimentalis, 32, 393-415.

(Manuscript received February 19, 1985; revision accepted for publication October 18, 1985.) 